\title{
Modern telecommunication systems and messengers as the alternative didactic platforms after Covid-19 pandemic lockdown
}

\author{
Anna Reznikova $^{1 *}$, and Victoria Posidelova ${ }^{2}$ \\ ${ }^{1}$ Don State Technical University, Rostov-on-Don, 344002, Russia \\ ${ }^{2}$ The Rostov Law Institute of the Ministry of Internal Affairs of Russia, Rostov-on-Don, 344015, \\ Russia
}

\begin{abstract}
Objectives: The article aims to discuss educational problems during the period of 2019-nCoV (SARS-CoV-2) pandemic lockdown in Russia and examines the peculiarities of innovative educational technologies within the modern educational paradigm in the context of teaching under a lockdown pressure. Special attention is paid to analyses of positive and negative aspects of lockdown distance learning, representing the concept of innovative pedagogy as a combined pedagogical approach that offers an alternative to existing teaching methods. The authors consider a lockdown educational experience to be a first step to a new era of educational technologies based on a principle of health safety and proper time management that could be achieved by application of online teaching methods. The authors describe the alternative didactic platforms such as Zoom and WhatsApp; define the term "distance learning" and the phenomenon designated by it. Special attention is paid to the consideration of a number of factors that hinder the introduction of innovative educational technologies and the reform of the educational system as a whole in the context of a lockdown.

Methodology: In our research we applied several methods that suit the objectives of the work: Statistical Data collection; Observation; Analysis.
\end{abstract}

\section{Introduction}

The year of 2020 turned out to be a year of great upheavals for the entire world community marked with a transition to a new era of development and evolution of society - the era of social disconnection and distance interaction. The fear of an unknown disease spread, the defenselessness of humanity before a new unexpected enemy forced the governments of the entire world community, one by one, to declare a total lockdown, which led to a complete stop of the life activity of society in the familiar way. A great biological conflict - a pandemic, the spread of a virus that has been registered as 2019-nCoV (SARS-CoV-2) or simply Covid-19, has changed the entire world.

A year has passed since the global threat to the life and health of our civilization appeared, millions of people in different countries of the world have become infected by

\footnotetext{
* Corresponding author: annreznikova@yandex.ru
} 
Covid-19 and eradicated the virus, but unfortunately, the disease has claimed the lives of hundreds thousands people around the world and today, a year later, humanity can boast of fundamental developments in the field of medicine, psychology, science and technology, but still the mechanism of launching the virus, its occurrence in the population, methods and means of treatment, the consequences of its presence in the human organism are not studied enough. Covid-19 spread affected not only the life and health of people, but also introduced the rules of a new reality: separation, social distancing, a ban on personal communication, the closure of educational institutions of all levels, the shutdown of production and trade facilities led to the most severe consequences for the economy of the world community countries.

A lockdown announced all over the world forced different companies and organizations to transfer the employees to a distance way of work; the implementation of a new safety work standard was the only possible way to ensure health safety to people under the circumstances of a virus rapid spread as it was reported as a highly contagious and virulent. Educational institutions of all levels had to turn to the distance learning as well. The closure of schools and universities due to the coronavirus disrupted the full educational process for about 1 billion students and schoolchildren in 160 countries [UN Secretary-General Antonio Guterres, 1], referring to data for mid-July, accounting for $91.3 \%$ of all students worldwide. In most countries, educational institutions have been closed completely or partially, and many students were transferred to distance learning. [2]

An emergency transition to a distance learning caused a huge amount of problems worldwide:

- insufficiency of technical equipment: efforts to provide education online failed dew to a poor Internet connection, lack of technical devices for education, lack of technical support etc.

- lack of a technical training of teachers under the pressure of a new reality: a large number of an old-school teacher were unable to rearrange themselves and turn to a new teaching model imposed by a new reality. It was a paradigm shift in instruction methods. [3]

- health restrictions in the case of long-lasting technical devices use: an objective obstacle to get high-quality online training was a health restriction. It was especially associated with visual problems and vascular diseases, as well as back problems.

- and even lack of funding to provide low-income families with technical means for distance learning. Unfortunately, this problem is one of the most serious because lack of funding deprives more than $250 \mathrm{mln}$. children all over the world from education not only in a distance way but in a contact as well.

A biological menace turned out to be a great threat to all mankind and a kind of a shock therapy that was taken as a start of a global educational crisis: a pedagogical society was not ready for a total lockdown and the first reaction was confusionand anxiety. A wise decision of the Russian President Vladimir Putin making a decree declaring the first week of the pandemic self-isolation as non-working hours made it possible for the specialists in the education sphere to react to the situation and organize the training within a new format considering the current circumstances.

So that, the pandemic distance learning turned out to be one of the greatest challenges in the history of educational paradigm development.

\section{Problem statement}

The research of innovative approaches in education has been of genuine interest to the scientific community since the early 70 s of the last century. Over the past few years, interest in the problem of innovative technologies and distance learning methods has 
increased significantly. Experts in the field of crisis research in the education sphere even in the beginning of the 70s of the XX century declared a possible global crisis in the teaching methodology and didactics and negative consequences for the education system lagging behind other social spheres in the framework of technical progress. Research of distance forms and methods of teaching in online mode is reflected in the works of such domestic and foreign scientists as N.B. Evtukh, T. Kulikova, M.Yu. Karpenko, D.M. Dzhusubalieva, S.P. Kudryavtseva, B.I. Shunevich, I. McPhee, D. Marks, I. Duffy, A. Okaz, M. Paechter, B. Mayer, etc. The main aspect of discussion always consists in debates of a distance learning pros and cons. In fact there is no definite answer whether it is good or evil as it is obvious that an implementation of any innovation should be started with a change of traditional methods that would take much effort. [4]

Fully online and hybrid or blended courses that integrate Information and Communication Technologies (ICT) and complement traditional classroom practice are on the rise nowadays in the field of language teaching. The aim of these courses is to offer flexible learning formats for learners of all ages in the way of tailor-made instruction which can adapt to their needs and expectations. They seem to be suited to diverse educational and social needs and provide, as well as demand, active engagement. [5]

Faculty commitment to instructional design and delivery is pivotal for creating effective virtual environments. The literature indicates that faculty needs to recognize that e-teaching requires design expertise and delivery skills (Salyers et al., 2014). Courses must be designed so that students could benefit from the interactive potential of online learning (Thorpe, 2002), so instructors require extensive training on how to utilize new technologies and adapt teaching methods to distance learning environment (Valentine, 2002). [6]

\section{Methods}

\subsection{Statistical Data Collection}

The authors analyze a large amount of statistical data:

- variety of dates announcing a total lockdown in a chain way (eg. China, considered to be an initial point of a disease spread, was the first to launch a campaign to restrict social activity and implementing social distancing: 08.02.2020; while the Russian Federation got a reprieve and implemented a lockdown system a month later: 16.03.2020);

- data on equality of distance learning opportunities (eg. the authors compare learning opportunities of capital students and backwoods students: it was stated that technical facilities of the capital higher educational institutions are much better than those in remote region; the teachers are easier to retrain and funding and e-learning organization is much better in the capital or central educational institutions).

\subsection{Observation.}

The authors define the phenomenon 'distance learning' taking in account the existing definitions, study the classification of existing distance learning means, classify the methodology of distance learning. 


\subsection{Analysis.}

The authors analyze the pros and cons of distance learning methodology, compared the traditional educational paradigm with a new-introduced mixed educational system combining traditional way of instruction with innovative pedagogy based on distance learning with implementation of communication systems and messengers as alternative didactic platforms.

\section{Results}

The main functions of the innovative activity of the teacher include progressive changes in the pedagogical process and its components, such as the goals, content of education, theories of education, means and techniques of teaching and development, etc. Unfortunately, a sudden and unexpected biological crisis has left neither time nor the opportunity for a thorough development of the methodology for distance learning with a complete rejection of the contact educational paradigm that is traditional for the Russian educational system. But anyway, the following innovative educational processes are to be distinguished:

- in the content of education;

- in technology;

- in the organization;

- to the control system;

- in educational ecology.

Innovations can be divided into systematic and random.

We should note that the pandemic was the starting point for the development of the latest educational technologies, the introduction of new technical skills, innovative teaching methods and creativity. Digitalization was the only possible way out of the current situation, when there was an urgent necessity to adjust the society life and an educational process by any means. The urgent development of the distance learning methodology was carried out almost without any delay, in order not to stop the educational process and not to slow it down. It should be noted that the Russian educational system coped with the task almost perfectly; all educational institutions were transferred to the distance learning mode and the curriculum was immediately reorganized according to a new life challenge.

In fact, the problem of implementation of distance learning into traditional educational paradigm is not new: it has been discussed thousands of times, taking in account all possible drawbacks of the online education. A phenomenon of distance learning is also defined by different scientists: some of them insist that a distance learning methodology is out of communication but dealing only with knowledge (Mayer, 1987), others prove that distance learning combine both knowledge and observable behavior (Slavin, 1994). Also the distance learning is defined as an educational process according to curriculum with teachers and students fully separated (Newby, Stepich, Lehman and Russell, 2000).

We consider that distance learning (e-learning) can be defined as a complex of educational technologies that fully meet the demands and requirements of the curriculum within a particular discipline or course by technical means ensuring continuous contactless interaction between a teacher and a student in case of geographical, time or pandemic constraints for contact study [2]. 


\section{Discussion}

Under a lockdown pressure the world community made an utmost effort to stabilize the situation in the sphere of education. The Russian Federation announced a self-isolation regime in March, 16, 2020 and since then a distance learning format had been lasting up to February 2021. It is necessary to point out that Russian pedagogical society coped with an unprecedented challenge almost perfect: the educational programs were reorganized considering new conditions; time-table was changed in order to reduce the burden from the harmful effects of distance learning technical gadgets and devices on the health of teachers and students; the leading universities administration took a decision to grant an open access to any electronic educational collections, databases, libraries that were charged before so students all over the world could continue educational process without any break no matter where they were locked down.

It should be noted that teaching society turned to distance educational technologies long before the pandemic but it was a bit too cautious: there were timid attempts to work via Skype and WhatsApp messenger. And we must admit that WhatsApp coped with the task to coordinate the educational activity of the teacher and students at the very beginning of selfisolation time. It was rather difficult at the very beginning to realize and estimate the burden of a new reality; nobody could even think of a long-lasting perspective of being captured by a virus. That's why all the coordination activity was conducted via WhatsApp messenger at first in a hope that a quarantine week would be over and we could get back to our routine life. Besides coordination the use of WhatsApp messenger chats has a lot of advantages:

- it gives an opportunity to unite the entire language group within the same goals. It creates a sense of belonging to something unifying and peculiar only to this particular community. Hence the feeling of significance arises in each member of the group, makes people to support each other that produces a sense of security allowing reveal their personality openly. This effect is very important in case of language learning as it reduces the fear of making a mistake during speaking or writing foreign language;

- another positive aspect is writing skills automatism. This is a utilitarian skill but extremely important because it is impossible to carry out full-fledged communication in any foreign language without it;

- Whatsapp messenger chat can also be used as a storage of different important information from links to some useful resources to textbooks, dictionaries and instructions necessary for study. It is an utmost convenience that helps to be always ready to improve your command $[7,8]$.

The teachers were given an opportunity to make their own choice of an educational platform and if in case of a Secondary school it was rather easy: the majority of schools in Russia based their distance learning in Uchi.ru and Russian electronic school platforms, the situation with the university differed. There is a vast variety of different telecommunication platforms and there for any university could make its own choice: so, the Rostov Law Institute of the Ministry of Internal Affairs of Russia and the Rostov Institute (branch) of All-Russian State University of Justice (RLA of the Ministry of Justice of Russia) have chosen TrueConf system as a didactic platform, while the teaching stuff of the Kuban State University implemented the Microsoft Teams system and Moodle platform. The Don State Technical University tested several telecommunication systems and the teaching stuff preferred to work via Zoom, Google Meet, Skype and Discord platforms. But we should admit that any of the telecommunication products has a lot of drawbacks. For instance, Zoom platform was announced to be unsafe though most of our colleagues were forced to use Zoom platform as a telecommunication didactic platform because it has one of the best and simplest interfaces among the similar platforms. Unfortunately, it is notoriously known 
to have a low level of personal data security and periodically pops up in the news in the context of another scandal due to the leak of personal data of users to the network. But taking in account our personal experience we could repeat and insist that we consider Zoom telecommunication system to be the best among others to meet the demands of distance learning especially humanitarian sciences based on speaking. First of all, Zoom platform was one of the most suitable telecommunications systems for distance learning due to its wide functionality. Zoom platform allows to include a wider audience coverage (online Zoom conference can include up to 250 people, if necessary), which is extremely important for conducting streamed lectures that are usually participated by a large number of listeners at the same time. Zoom also provides audio and visual contact with students and simultaneous demonstration of the teacher's desktop, presenting any type of online task, such as video presentation, listening with subtitles if necessary, PowerPoint presentation, online knowledge test and many other different types of tasks. Moreover, the demonstration of the presentation and any other type of task does not limit the live communication of the student and the teacher: they can see each other face to face and maintain visual contact. This facility helps to reduce an audio burden, since the imperfection of the Internet connection often leads to a situation when the teacher is forced to interrupt a lecture or seminar and with a question like " Can you hear me well?", "Can you see me?" and so on, to make sure that the listeners adequately perceive the information given by the lecturer.

Another platform widely used by a teaching stuff of the Don State Technical University has become Skif (www.test.skif.donstu.ru ) - an educational platform with a well-packed interface and logical subdivision of electronic courses helping both students and teachers not to stop educational activity and complete all the necessary tasks online.It should be marked that Skif system was created in advance and long before the pandemic started. During a lockdown period it was hard to overestimate the importance of this database containing the collections of lectures, practical tasks and video presentations according to different disciplines. It was seriously enhanced by an effort of a teaching stuff of the Don State Technical University: the number of electronic courses rose from about 200 up to 1000 in a short period of a non-working week beforeself-isolation without any reduction of the academic value.

Skif platform based on a Moodle form is one of the best interactive platforms for distance learning within a high school: it has a smart interface, logical structure, variety of possible task and offers a lot of opportunities both for teachers and students to interact within an educational activity.

The personal experience of many teachers makes it possible to declare a pandemic distance learning period a real examination for the whole pedagogical society and it could be admitted as successfully passed. Though we learnt our lessons and could easily present the results of a pandemic distance learning taking in account pros and cons of it.

The first advantage of a distance learning to be mentioned is expanding of educational borders by implementing distance learning and online courses into traditional method of instruction: before the pandemic urgent necessity online classes were given mostly with the purpose of students' checkout in a testing mode within some particular subject. The total implementation of distance learning practice widens the opportunity of students offering them a large amount of educational courses, both supplementary and basic.

Another positive point is an opportunity to be taught from any possible location: it is a very important advantage for the students having a job and obtaining a higher education in adulthood. There is no need to go to an educational institution, at least, do it often. This is especially true for students from the regions: it leads to a reduction in financial costs, makes it possible to get a diploma from any capital or foreign universities.

In addition, we should note another interesting peculiarity that distance learning has identified: the attendance of online classes is significantly higher than the attendance of 
traditional contact classes. What is more, distance learning has made a special contribution to the formation of students ' professional competence based on an individual approach to the task, the need to find an algorithm for solving a particular problem by themselves, necessity to use additional sources of information that are to be found and worked out independently. The peculiarities of the process disciplines students significantly and contribute to the proper time management.It is very important to motivate students to work actively non-stop. It sounds unexpected but it turned out students' awareness that constant and hard work during e-learning could bring double profit:

- primarily, a distance learning gave an opportunity to spend more time for study as well as for entertainment due to a better time management;

- e-learning provided a wider range of possibilities of an individual creative work based on individual approach to preparation to distance classes;

- e-learning involved the most part of students into a self-study model according to which a student takes a responsibility of a preparation quality to himself personally. This aspect, to our opinion, became one of the most important motivating points for a students' progress during a pandemic distance learning.

But still it's important to recognize displays of procrastination and laziness among students with different academic performance rates [9].

The most common advantages of distance learning given by students are the following:

- an opportunity to study at work,

- the possibility to study in time that the student determines himself,

- the possibility to plan work and study mode individually,

- flexible hours and the permission not to attend University daily,

- low cost of study in case of distance learning,

- the possibility to obtain a curriculum by a disabled people. [2]

Generally, we can enumerate the following aspects of distance learning:

- accessibility: any student could get an opportunity to access to any possible educational and information networks, databases and knowledge banks for students allowing them to achieve the scores in training programs individually in accordance with their needs and intellectual level.

- flexibility: the educational process can be easily divided into modules in order to simplify the process and give a student time to achieve his goals within every separate module to move on slowly but surely;

- motivation: students should be motivated in their study by self-progress in practical application of theoretical basics presented via distance learning or self-study;

- learning mobility: any student can get higher education no matter where he is, what social status he has and what physical restraints he may have;

- individuality: any student should be considered as a personality with his individual peculiarities that require an individual approach.

Unfortunately, besides positive aspects of distance learning we should draw attention to some negative issues. According to a survey made by RAEX in order to find out distance learning opportunities an all-Russian focus group of six thousand students was formed and questioned.

Generally, the results of the survey are the following: it was predictable that technical support and didactics of the capital higher educational institutions would be much better than in regional universities. Although it's interesting that over $70 \%$ of a focus group members pointed out a lack of communication with group mates and a teacher as a main drawback of an educational process in a distance mode;

- $36,9 \%$ of respondents reported a challenge of self-control and self-organization; 
- $58,1 \%$ of students drew attention to the problem of technical support and weak programming of educational apps (it should be noted, that the percentage of students dissatisfied with technical support was higher in the regions $-71,2 \%$ vs. $47 \%$ in Moscow). [10]

It should be pointed out that distance learning requires students and teachers to have a completely different approach than regular daytime lessons. As demonstrated by practical experience, this is a very demanding form of education and therefor some other negative aspects arise:

- students and many teachers have little or no experience with this form of education. It is important to keep in mind age and technical illiteracy of some teachers; it is obviously impossible or extremely difficult for them to learn the latest computer technologies in the shortest possible time that's why teachers feel they can use the same pedagogical and didactic practices as in full-time teaching. As opposite to full-time teaching, it is necessary to provide an extensive preparation for the distance and combined forms. Students must already have all study materials, assignment of correspondence tasks, technically prepared control systems, means of communication, and so on. However, this requires a lot of work both technically and methodically and didactically. [11]

- teaching requires students to be highly motivated and able to deal with time efficiently, complex and demanding preparation of teaching and study materials.

Also it's necessary to add that e-learning delivers even more fundamental disadvantages besides those already discussed:

- more considerable difficulty in understanding some terms,

- retaining motivation for the study.

- safety of personal data

- stable and constant operation of technical devices, software and multimedia educational platforms.

Also one of the most important facts is a lack of communication between all the participants of an educational process. It is rather important issue in teaching any linguistic discipline: it is extremely difficult to stay motivated within restricted opportunities and speaking lack. According to Florence Martin and Doris U. Bolliger, activities that enhance engagement "assist students in feeling connected and can create a dynamic sense of community" [12]. In this case it was extremely important to provide students and teachers with the feeling of belonging to a society (community) and not to feel lost and lonely in self-isolation period [13]. And generally the aspect of lack communication can be divided into two problems: a technical problem and psychological one [14].

The first technical problem is a system error of resources. In almost all communication systems with a large number of users, there were interlocks or even total shutdowns. Though it concerns almost any didactic platform, messenger or telecommunication system the problems occurred were different. It was the huge overload of platforms due to the mass users' connection that caused technical failures, which were accompanied by system interlocks and shutdowns. As a result, students had to work with video and audio modes disconnected.

Speaking about a psychological aspect of the problem we should note that there was a lack of speech competitiveness. It should be admitted that lack of speech activity does not contribute to the competitive spirit that usually reigns in contact classes [15].

But the problem of introducing of a fully obtained educational platform is still opened and requires a salvation in a shortest possible time as we could clearly understand now that our world is changing rapidly and we should gain a necessary speed not to lag behind it and provide our life with all the necessary conditions for survival under any possible lockdown pressure. 


\section{Conclusion}

In conclusion it is necessary to point out that our country coped with the task and organized training during the pandemic at a very high level. Moreover, it is obvious now that distance learning is a future of our educational paradigm and the pedagogical society should admit it. The combination and compilation of both traditional and innovative methods of instruction will bring our educational system to a new high point improving it and arrange in a better way. Thus, the introduction of rational, balanced and well-founded innovative educational technologies is the cornerstone in building a high-quality, modern and affordable educational platform. Only in this case will we be able to respond adequately to all the challenges of modern society, to form the consciousness of the new millennium in the younger generation and to look to the future with new hope.

\section{References}

1. A. Guterres, According to the UN, COVID-19 disrupted the studies of a billion students and schoolchildren. Retrieved from: https://www.interfax.ru/world/720181 last accessed 2021/03/11(2020)

2. A. Reznikova, T. Kudinova, R. Patuykova, N. Olomskaya, O. Dyshekova, E3S Web of Conferences 210, 18037 (2020). ITSE-2020 Retrieved from: https://www.e3sconferences.org/articles/e3sconf/abs/2020/70/e3sconf_itse2020_18037/e3sconf_itse20 20 18037.html last accessed 2021/03/16 https://doi.org/10.1051/e3sconf/202021018037

3. P. Dubey, D. Pandey, International Journal of Indian Psychology 8 (2), 43-46 (2020). DOI:10.25215/0802.204.

4. S. Bekniyazova, Theoretical \& Applied Science 9 (89), 257-261 (2020)

5. M. Arrosagaray, M. González-Peiteado, M. Pino-Juste, and B. Rodríguez-López, $\begin{array}{lllll}\text { Computers } \& \quad \text { Education } & \text { 134, } & \text { (2019). }\end{array}$ https://doi.org/10.1016/j.compedu.2019.01.016

6. T. Markova, I. Glazkova, E. Zaborova, Procedia - Social and Behavioral Sciences 237, 685-691 (2017). https://doi.org/10.1016/j.sbspro.2017.02.043

7. A. Reznikova, A. Vnukovskaya, The Bulletine of the Ufa Law Institute of the Ministry of Internal Affairs of Russia 4 (86), 183-187. (2019)

8. T. Usmanova, The world of pedagogy 5 (22), 11-17 (2018)

9. D. Dautov, Procrastination and laziness rates among students with different academic performance as an organizational problem, E3S Web of Conferences 210, 18078 (2020). ITSE-2020 last accessed 2021/03/16 Retrieved from:https://www.e3sconferences.org/articles/e3sconf/abs/2020/70/e3sconf_itse2020_18078/e3sconf_itse20 20_18078.htmlhttps://doi.org/10.1051/e3sconf/20202101018078

10. Distance learning 2020 Retrieved from: https://raexa.ru/researches/distance_education/2020 last accessed 2021/03/15 (2020)

11. M. Hannay, T. Newvine, Journal of Online Learning and Teaching 2 (1), 1-11 (2006)

12. D.U. Bolliger, F. Martin, Distance Education 39 (4), 568-583 (2018). doi: 10.1080/01587919.2018.1520041

13. E. Rudenko, R. Bachieva, A. Aligadzhieva, Z. Temirhanova, A. Archilaeva, E3S Web of Conferences 210, 18038 (2020). ITSE-2020 last accessed 2021/03/16 Retrieved from: 
conferences.org/articles/e3sconf/pdf/2020/70/e3sconf_itse2020_18038.pdfhttps://doi.o $\mathrm{rg} / 10.1051 / \mathrm{e} 3$ sconf $/ 202021018038$

14. E. Kopshukova, V. Malakhova, A. Lazareva, Professional Discourse \& Communication 2 (2), 83-88 (2020.)

15. L. Vlasenko, I. Ivanova, V. Pulyaeva, International Journal of Applied Exercise Physiology 8 (2.1), 1023-1031 (2019). 